OPEN ACCESS

Edited by:

Amalia Forte,

Università degli Studi della Campania

"Luigi Vanvitelli" Caserta, Italy

Reviewed by:

Anna Zampetaki,

King's College School,

United Kingdom

Daniela Carnevale,

Sapienza Università di Roma, Italy

*Correspondence:

Lars Maegdefesse

lars.maegdefesse/@tum.de

Specialty section: This article was submitted to

Vascular Physiology,

a section of the journal

Frontiers in Physiology

Received: 28 April 2017 Accepted: 02 June 2017

Published: 16 June 2017

Citation:

Li Y and Maegdefessel L (2017) Non-coding RNA Contribution to

Thoracic and Abdominal Aortic

Aneurysm Disease Development and

Progression. Front. Physiol. 8:429.

doi: 10.3389/fphys.2017.00429

\section{Non-coding RNA Contribution to Thoracic and Abdominal Aortic Aneurysm Disease Development and Progression}

\author{
Yuhuang $\mathrm{Li}^{1}$ and Lars Maegdefessel ${ }^{1,2 *}$ \\ ${ }^{1}$ Vascular Biology Unit, Department of Vascular and Endovascular Surgery, Klinikum rechts der Isar der Technical University \\ of Munich, Munich, Germany, ${ }^{2}$ Department of Medicine, Karolinska Institutet, Stockholm, Sweden
}

Multiple research groups have started to uncover the complex genetic and epigenetic machinery necessary to maintain cardiovascular homeostasis. In particular, the key contribution of non-coding RNAs (ncRNAs) in regulating gene expression has recently received great attention. Aneurysms in varying locations of the aorta are defined as permanent dilations, predisposing to the fatal consequence of rupture. The characteristic pathology of an aneurysm is characterized by progressive vessel wall dilation, promoted by dying vascular smooth muscle cells and limited proliferation, as well as impaired synthesis and degradation of extracellular matrix components, which at least partially is the result of transmural inflammation and its disruptive effect on vessel wall homeostasis. Currently no conservative pharmacological approach exists that could slow down aneurysm progression and protect from the risk of acute rupture. In the recent past, several non-coding RNAs (mainly microRNAs) have been discovered as being involved in aneurysm progression throughout varying locations of the aorta. Exploring ncRNAs as key regulators and potential therapeutic targets by using antisense oligonucleotide strategies could open up promising opportunities for patients in the near future. Purpose of this current review is to summarize current findings and novel concepts of perspectivly utilizing ncRNAs for future therapeutic and biomarker applications.

Keywords: aortic aneurysm, non-coding RNA (ncRNA), MicroRNA (miRNA), gene expression regulation, vascular diseases, long non-coding RNA (IncRNA)

\section{INTRODUCTION}

Aortic aneurysms (AAs) are asymmetrical dilations of the aorta with diameters $>1.5$ times the normal size (Kent, 2014). They are most commonly located in the infrarenal abdominal aorta but can also be found in the thoracic aorta. The overall prevalence of abdominal AAs (AAAs) is 6\% in men and $1.6 \%$ in women (Li et al., 2013); the incidence for thoracic AAs (TAAs) is roughly 10/10,000 in our population (Elefteriades et al., 2015). Fatal outcomes due to aortic rupture occur when intraluminal pressures exceed the capacity of the arterial wall, with mortality rates as high as $80 \%$ (Golledge and Norman, 2011). It is estimated that aneurysm ruptures account for nearly 15,000 deaths in the United States annually (Lloyd-Jones et al., 2009). Most of these fatalities are due to abdominal aneurysms, with thoracic and thoracoabdominal aneurysms accounting for 1 to $4 \%$ of all aneurysm-related deaths (Lindsay and Dietz, 2011). The asymptomatic characteristic of 
aneurysms makes their assessment challenging. Unless AAs rapidly increase or acutely rupture, or thrombi embolize into the distal arterial system, AAs behave as a silent disease (Kent, 2014).

Currently, the only available treatment of AAs is surgical intervention, such as prosthetic replacement (open surgery) or strengthening (endoprosthesis) of the aorta (Golledge et al., 2006). The latter endovascular repair has become the preferable option in the past decade, accounting for $\sim 70 \%$ of AA procedures performed in Europe and North America (Schanzer et al., 2017; Williams and Brooke, 2017). However, clinically surgical intervention is only recommended when aneurysms are prone to rupture, since both interventional procedures carry surgical risks (Kent, 2014). Unfortunately, no effective pharmacological approaches have been approved to limit the progression or risk of aneurysm rupture in humans (Golledge et al., 2006). Obtaining a better understanding of the cellular mechanisms driving aneurysm development and progression is not only essential to fill this gap but is also important to identify new biomarkers and therapeutic targets.

This review focuses on the contribution of non-coding RNAs (ncRNAs) to AA development and progression, and discusses their potential therapeutic value in this context. With the completion of human genome project in 2003, the "proteincentered" dogma of molecular biology was challenged with the discovery that while $>98 \%$ of our genome is "non-coding," it is still transcribed (Esteller, 2011). Accumulating evidence has shown that this refined orechstrating system of ncRNA mediators are powerful regulators of various aspects of cellular function and disease progression (Vidigal and Ventura, 2015; Engreitz et al., 2016; Figure 1). In general, ncRNAs are classified, based on an arbitrary cut-off size of 200 nucleotides (nt), into separate groups of small ncRNAs and long non-coding RNAs (lncRNAs). MicroRNAs (miRNAs) are the most well-studied group of small ncRNAs, and $\sim 22 \mathrm{nt}$ in length, whereas lncRNAs are larger than $200 \mathrm{nt}$ and their distinct functions being largely unexplored (Cech and Steitz, 2014).

\section{CELLULAR MECHANISMS BEHIND AORTIC ANEURYSM DEVELOPMENT AND PROGRESSION}

The lack of pharmacological approaches to limit aneurysm progression and rupture mandates a better understanding of the pathogenesis and cellular mechanisms of aneurysm development. New mechanistic insights may identify potential therapeutic targets. Here, we summarize the pathologic mechanisms and related molecular characteristics behind thoracic and abdominal aneurysm development and progression.

\section{THORACIC AORTIC ANEURYSM}

Despite the common phenotypic manifestations with AAAs (discussed below), TAAs exhibit a strong heritable pattern, with different pathophysiologies, risk factors, and evolutionary progression. For example, the known risk factors most associated with AAAs include cigarette smoking, increasing age, hypertension, hyperlipidemia, and atherosclerosis, whereas TAAs are primarily associated with connective tissue diseases, bicuspid aortic valve disease, and familial thoracic aneurysm syndrome. Nevertheless, perturbed extracellular matrix (ECM) homeostasis, transforming growth factor- $\beta$ (TGF- $\beta$ ) signaling, and vascular smooth muscle cell (SMC) plasticity and survival have been proposed as important processes in TAA pathogenesis (Verstraeten et al., 2017). Recently, a genetic predisposition to TAAs has been identified, highlighting the dominant role of gene mutations in the TGF- $\beta$ signaling cascade and SMC contractile apparatus (Isselbacher et al., 2016). Additionally, research in experimental aneurysms has revealed hyperstimulation of the TGF- $\beta$ pathway in TAAs (Neptune et al., 2003; Habashi et al., 2006), likely the result of genetic perturbations. Mutations of TGF- $\beta$ signaling molecules are proposed to upregulate counterregulatory pathways, such as those involving mitogen-activated protein kinase (MAPK), which can directly drive aneurysm development (Holm et al., 2011). Interestingly, TGF- $\beta$ is poorly expressed in human AAAs and appears to play a protective role in their development. The modulation of TGF- $\beta$ signaling prevents AAA formation in both elastase infusion and angiotensin II (AngII) perfusion animal models of AAA (Wang et al., 2010, 2013). On the other hand, mutations in the SMC contractile apparatus result in a loss of contractile structure, which is essential for the maintenance of an intact focal adhesion complex and the integrity of the ECM (Milewicz et al., 2008). It is currently unclear whether the relationship between such a contraction vasculopathy and TGF- $\beta$ dysregulation correlates with - or is a precipitating cause of TAAs (Isselbacher et al., 2016), considering that TGF- $\beta$ can both induce a phenotypic switch in SMCs and stimulate the secretion of matrix-degrading enzymes, such as matrix metalloproteinases (MMPs), from these cells(Renard et al., 2013).

\section{ABDOMINAL AORTIC ANEURYSM}

The defined mechanisms underlying AAAs are as well incompletely understood. AAA formation is thought to be a complex process, involving all vascular cell subtypes (Maegdefessel et al., 2013). The pathological features are characterized by endothelial dysfunction, chronic adventitial and medial inflammatory cell infiltration, ECM degradation, elastin fragmentation and medial devitalization, as well as SMC phenotype alterations (early stages) and apoptosis (late stages; Shimizu et al., 2006). Work in both common small animal models and humans has indicated that AAA development involves local inflammation and the infiltration of monocytes/macrophages, neutrophils, mast cells, and $\mathrm{T}$ and B lymphocytes (Sun et al., 2007). These infiltrating cells secrete various inflammatory cytokines and chemokines, such as interleukin (IL)-1 $\beta$, IL-6, tumor necrosis factor (TNF)- $\alpha$, and monocyte chemoattractant protein-1 (MCP-1), which can induce the activation of MMPs, particularly MMP-2 and MMP-9 (Golledge et al., 2006). These events contribute to ECM degradation and SMC depletion, leading to AAA progression and rupture. 


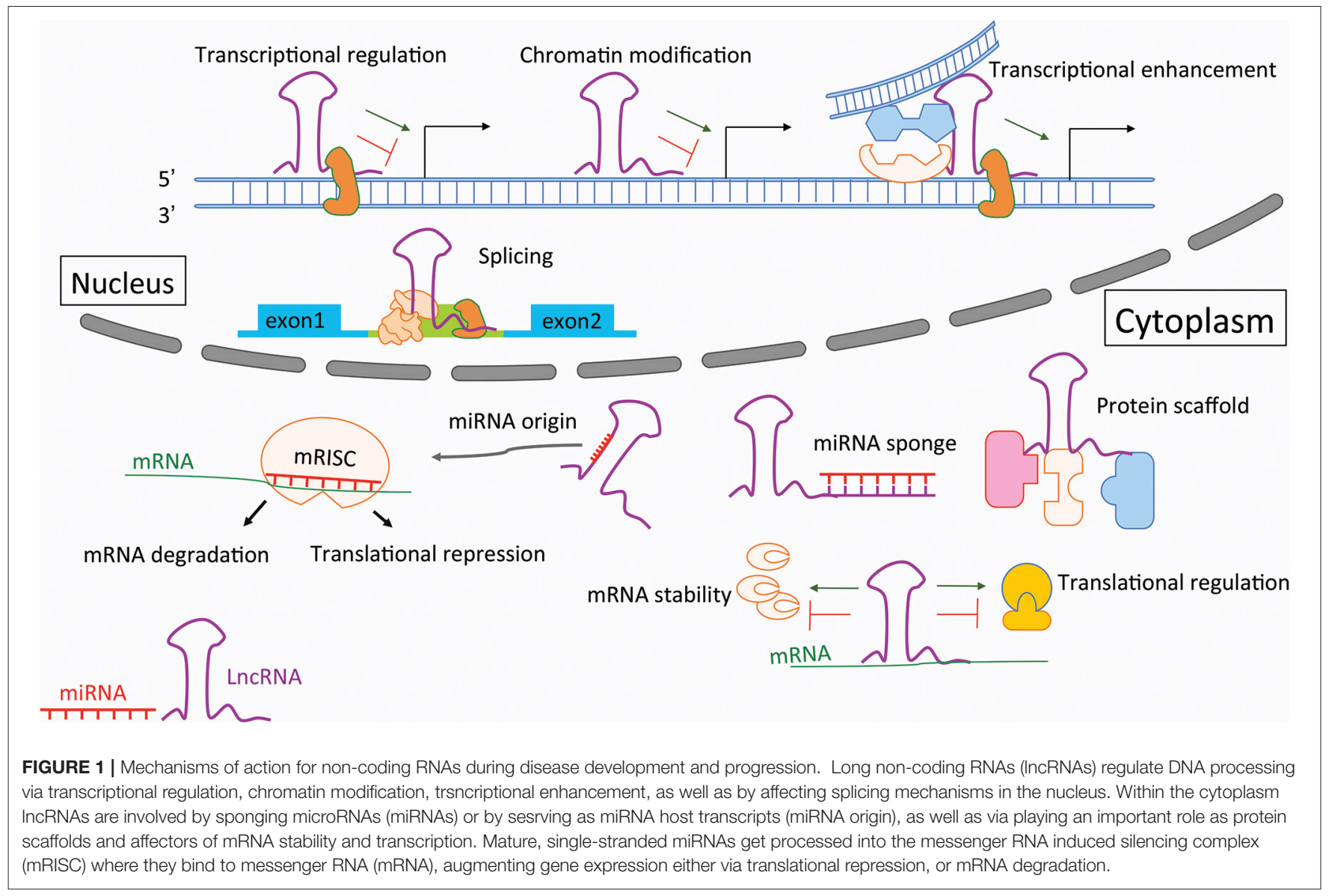

\section{NON-CODING RNAS}

ncRNAs are RNA molecules that are not translated into protein products. They can be functionally classified into the following subgroups: gene expression regulation (miRNAs, piRNAs, lncRNAs), RNA maturation (snRNAs, snoRNAs), and protein synthesis (rRNAs, tRNAs; Fu, 2014). In this section, we will review some important aspects of miRNAs and lncRNAs, and highlight their regulatory roles in AA development and progression.

\section{MICRORNAS}

MicroRNAs (miRNAs) are endogenous RNAs of $\sim 22 \mathrm{nt}$ that post-transcriptionally repress the expression of target genes, usually by binding to the $3^{\prime}$ untranslated region (UTR) of messenger RNA (mRNA). The stepwise progression of miRNA maturation has already been established (Lee et al., 2002, 2003). The first step is nuclear cleavage of primary-miRNA (primiRNA) by Drosha RNase III endonuclease, resulting in a 60-70-nt stem-loop intermediate known as miRNA precursor (pre-miRNA), which is then actively transported from the nucleus to the cytoplasm by guanosine triphosphate (GTP)binding nuclear protein Ran (RAs-related Nuclear protein RanGTP) and the export receptor exportin-5. In the cytoplasm,
pre-miRNA is further processed by the enzyme Dicer, producing an imperfect siRNA-like duplex that composes the mature miRNA. Fully processed miRNAs associate with, and serve as specificity determinants for, the Argonaute (Ago) family of proteins within the RNA-induced silencing complex (RISC; Hutvagner and Zamore, 2002). At sites with extensive pairing complementarity, miRNAs can direct Ago-catalyzed mRNA cleavage. More commonly, though, they direct translational repression, mRNA destabilization, or a combination of these two processes (Bartel, 2009; Djuranovic et al., 2011).

MiRNAs have emerged as key post-transcriptional regulators of gene expression in the past decade, playing important roles in various biological processes and in disease development and progression(Bartel, 2004; Ebert and Sharp, 2012; Mendell and Olson, 2012). For AAs in particular, several miRNAs have been identified as crucial regulators, orchestrating the functions of all subtypes of vascular cells (Table 1). Endothelial cell (EC) dysfunction and leukocyte infiltration, degradation of the ECM, and SMC depletion are regarded as three pathological hallmarks of AAAs (Guo et al., 2006). As the aneurysm miRNA signature may differ depending on disease localization and morphology (Busch et al., 2016), one should act with caution when elucidating and comparing deregulations examined in human aneurysms, animal models, or cultured cells in vitro. 


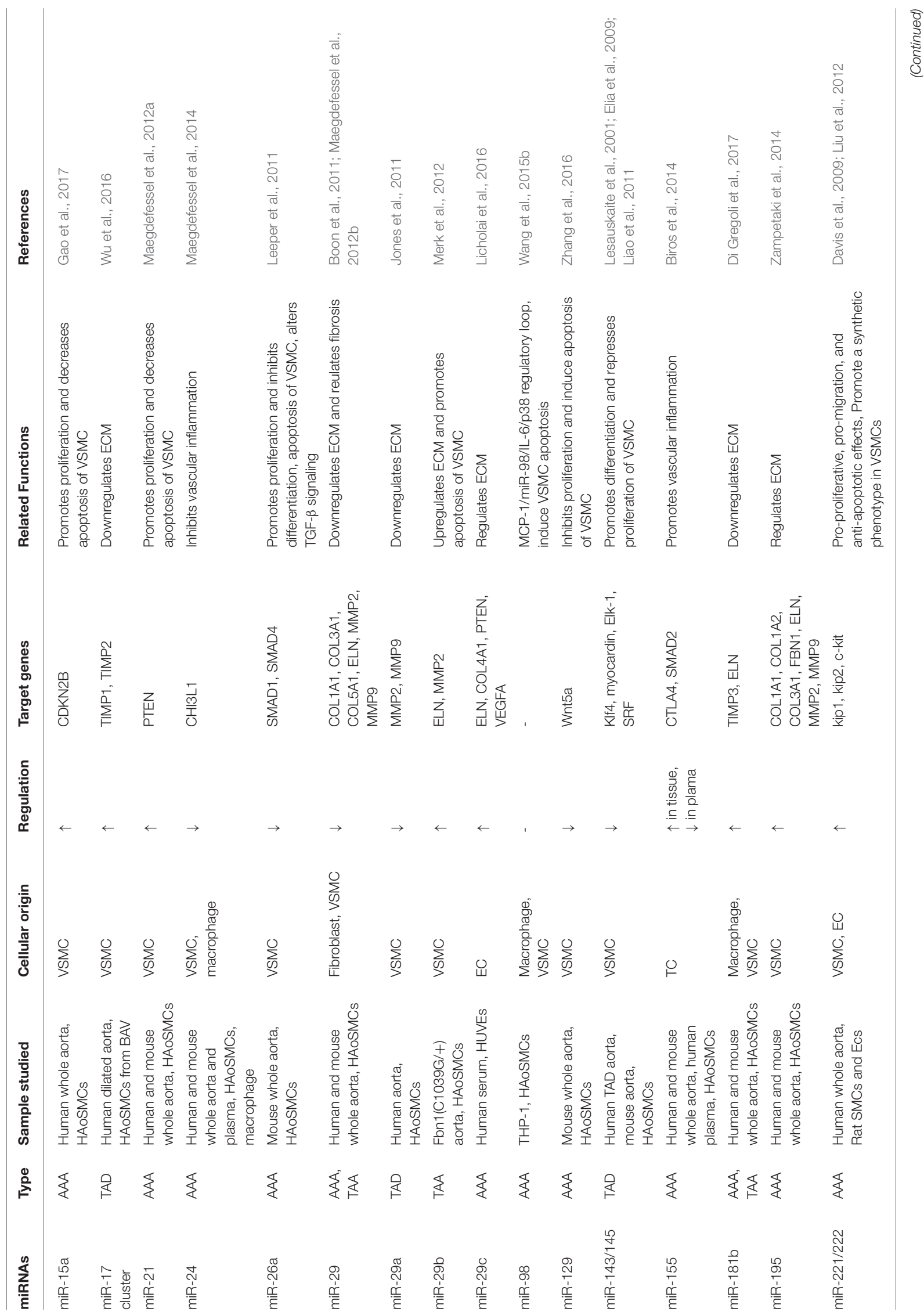




\section{MIRNAS, ENDOTHELIAL DYSFUNCTION, AND VASCULAR INFLAMMATION}

ECs are the first cell sensors exposed to pathologic factors, such as hyperlipidemia and turbulent flow shear stress, in the lumen of the aorta. To address the role of endothelial miRNAs in AAA development, Kim et al. (2014) utilized the mouse AngII infusion model of AAAs, one of the most important experimental platforms to study the pathophysiology of AAAs. Using an miRNA microarray platform, the authors experimentally confirmed the upregulation of miR-712/205 in ECs as well as in the medial layer of the aorta. Of note, the two key inhibitors of MMPs, tissue inhibitor of metalloproteinase 3 (TIMP3) and reversion-inducing-cysteine-rich protein with kazal motifs (RECK), which lead to both the activation of MMPs in the aortic wall and the development of AAAs in the mouse AngII infusion model, were validated as direct targets of miR-712. In addition, the manipulation of both AngII and miR-712/205 affected the adhesion of circulating leukocytes, further highlighting the therapeutic potential of targeting this pathway, while implying that other mechanisms are involved. Furthermore, in human vascular ECs, other genes related to ECM synthesis and maintenance of ECM integrity, such as elastin (ELN), collagen type 4 alpha 1 (COL4A1), phosphatase and tensin homolo (PTEN), and vascular endothelial growth factor A (VEGFA), were recently identified as targets of miR-29c and are significantly elevated in the sera of AAA patients (Licholai et al., 2016).

Subsequent inflammatory cell infiltration may be facilitated by miR-155, whose levels were found to be highly increased in AAA biopsies and circulating sera in AAA patients (Biros et al., 2014). It is believed that miR-155 not only promotes chronic inflammation by enhancing $\mathrm{T}$ cell development via the downregulation of cytotoxic T-lymphocyte associated protein 4 (CTLA4), but also blocks mothers against decapentaplegic homolog (SMAD2) translation and protein synthesis during the regulation of TGF- $\beta$ signaling, leading to AAA development. Similarly, miR-181b was shown to endow macrophages with more invasive and proliferative capabilities to control aneurysm progression via the negative regulation of tissue inhibitor of MMP-3 expression (TIMP3; Di Gregoli et al., 2017). Moreover, miR-223, a novel regulator of inflammation that inhibits proinflammatory pathways and enhances anti-inflammatory responses, was dysregulated in AAAs (Kin et al., 2012) and negatively correlated with MCP- 1 , TNF- $\alpha$, and TGF- $\beta$ expression in diseased aortic tissues(Kanematsu et al., 2011; Lee et al., 2013). Recently, miR-103a (Jiao et al., 2017) was reported as an "anti-aneurysmal" miRNA that suppresses inflammation within the aortic wall, limiting AAA formation and progression by downregulating the protease ADAM Metallopeptidase Domain 10 (ADAM10).

Our lab discovered miR-24 as a key regulator of vascular inflammation and AAA pathology (Maegdefessel et al., 2014). Before elucidating the highly conserved miR-23b-24-27b cluster in AAA diseases, others have shown that this miRNA family is involved in postinfarction cardiac angiogenesis (Fiedler et al., 2011), cardiomyocyte survival (Qian et al., 2011), cancer 
(Hatziapostolou et al., 2011; Qian et al., 2011), and atherosclerosis (Geng et al., 2016). The miR-23b-24-27b cluster has been further linked to inflammation by its ability to modulate the nuclear factor kappa-light-chain-enhancer of activated B cells (NF-кB) pathway in macrophages (Thulasingam et al., 2011). In addition, Hatziapostolou et al. (2011) demonstrated an miRNAinflammatory feedback loop, consisting of miR-124, IL-6R, signal transducer and activator of transcription 3 (STAT3), miR-24, and miR-629, in which the systemic administration of miRNAs prevented and suppressed hepatocellular carcinogenesis by the induction of tumor-specific apoptosis without toxic side effects.

In our own study (Maegdefessel et al., 2014), we profiled miRNA expression and validated the downregulation of the miR23b-24-27b cluster in murine AAA models, finding that miR24 displayed the most significant inverse regulation with its predicted targets. Human AAAs also show evidence of miR24 downregulation, which correlates inversely with aneurysm size. Further analysis suggested 'chitinase 3-like 1' (Chi311), a mediator/marker of inflammation, as an intriguing miR-24 target. Chi3l1 is secreted by differentiated macrophages in early stage atherosclerotic lesions and modulates SMC proliferation and migration (Rehli et al., 2003). In the context of AAAs, miR-24-Chi3l1 interactions appear to have broad effects on all cells present in the aortic wall, such as the regulation of macrophage survival and cytokine synthesis, promotion of aortic SMC migration and cytokine production, and stimulation of adhesion molecule expression in vascular ECs. Furthermore, overexpression of miR-24 in murine models was able to significantly decrease Chi3l1 levels, leading to arrested AAA development and reduced immune responses and cytokine activities, suggesting that miR-24 downregulation contributes to aneurysm growth. In contrast, the inhibition of miR-24 was shown to accelerate AAA progression by augmentation of the degree of inflammatory and apoptosis-related responses.

Consistent with findings related to miR-24 and the inflammation loop, Pua et al. (2016) provided evidence that miR-24 and miR-27 suppress allergic inflammation and target regulators of $\mathrm{T}$ helper 2 cell-associated cytokine production. These data suggest that miR-24 may be involved in leukocyte infiltration during aneurysm development. Another study from Geng et al. (2016) examined the pathological consequences of subclinical endotoxemia during both the low-grade inflammatory polarization of monocytes and the progression of atherosclerosis. These authors observed that subclinical endotoxemia was able to shift monocytes into a nonresolving inflammatory state, with elevated levels of lymphocyte antigen 6 complex locus C (Ly6C), chemokine (C-C motif) receptor 5 (CCR5), and MCP-1, and reduced levels of scavenger receptor class B member 1 (SR-B1), due to the disruption of homeostatic tolerance by elevated miR-24 levels and reduced levels of the key negative-feedback regulator interleukin-1 receptor-associated kinase (IRAK)-M. MiR-24 targets SMAD4, which is required for the expression of IRAK-M and the key lipid-processing molecule SR-B1. IRAK-M deficiency in turn leads to elevated miR-24 levels, sustaining the disruption of monocyte homeostasis and aggravating atherosclerosis. Another study recently confirmed the role of miR-24-Chi3l1 interactions in Staphylococcus aureus-stimulated macrophages (Jingjing et al., 2017). MiR-24 was found to decrease both M1 macrophage polarization and production of proinflammatory cytokines, and induce both M2 macrophage polarization and secretion of anti-inflammatory factors. These actions are mediated by the direct suppression of Chi3l1 and the inhibition of the MAPK pathway.

\section{MIRNAS AND SMOOTH MUSCLE CELL HOMEOSTASIS}

SMCs are the predominant cells in the tunica media of the aorta and are essential for the maintenance of aortic structure and function. The phenotype of SMCs can change from a contractile (differentiated) to a synthetic (dedifferentiated) state, and vice versa, in response to changing environmental conditions. The differentiated phenotype is characterized by high levels of contractile gene expression, with low rates of proliferation, migration, and ECM synthesis; the dedifferentiated phenotype has the opposite features. Dysregulation of both phenotype switching and SMC apoptosis contributes to the development and progression of AAs (Henderson et al., 1999; Ailawadi et al., 2009). Previous studies have revealed that SMC homeostasis is intensively regulated by a vast array of miRNAs (Table 1).

Leeper and collaborators (Leeper et al., 2011) were able to prove that miR-26a is an important regulator of the SMC phenotype. They performed a microarray-based study during human aortic SMC differentiation in vitro and showed that miR26a was the highest-ranked significant miRNA present. SMC behavior was evaluated by the modulation of miR-26 via the transfection of either pre-miR or anti-miR. The decreased level of miR-26a was associated with a reduction in SMC proliferation and migration, and a significant increase in $\mathrm{H}_{2} \mathrm{O}_{2}$-induced apoptosis. Mechanistically, miR-26a targeted the expression of SMAD1 and SMAD4, members of the TGF- $\beta$ signaling cascade, and thus affected AAA development. Moreover, the expression of miR-26a was found to be progressively downregulated in two murine AAA models, suggesting that miR-26a may represent a novel therapeutic target in conditions of pathologic aneurysmal dilation.

MiR-221/222, which are highly expressed in SMCs and ECs, seem to have a cell-specific effect on the aorta. Liu et al. (2012) isolated SMCs and ECs from the aortas of male Sprague-Dawley rats and assessed the cellular responses to miR-221/222. Interestingly, these miRNAs had pro-proliferative, pro-migratory, and anti-apoptotic effects on SMCs - but the completely opposite effect on ECs. MiR-221/222 appears to directly target and downregulate p27 (Kip1), p57 (Kip2), and c-Kit, three proteins that are involved in key processes of cell differentiation, proliferation, migration, and apoptosis, and are also differentially expressed in SMCs and ECs. Consistent with these data, Davis et al. (2009). identified that miR-221 was critical for the platelet-derived growth factor (PDGF)-mediated induction of cell proliferation by downregulating the expression of p27 (Kip1) and c-Kit. 
In our previous work (Maegdefessel et al., 2012a), we discovered the essential role of miR-21 in SMC homeostasis during AAA development. MiR-21 is highly expressed in SMCs and is known to be involved in the regulation of SMC biology by targeting several cell fate-determination genes, such as PTEN (Horita et al., 2011), programmed cell death 4 (PDCD4; Liu et al., 2010), and B cell lymphoma 2 (BCL2; Ji et al., 2007). Ji et al. (2007) found that miR-21 was one of the most upregulated miRNAs in the vascular wall after balloon injury, and that miR-21 depletion significantly decreased neointima formation, suggesting that miR-21 serves as an important regulator of neointimal hyperplasia, which results from an imbalance between SMC proliferation and apoptosis. Indeed, these authors confirmed that PTEN and BCL2, two important signaling molecules associated with SMC growth and apoptosis, were miR-21 targets. In addition, evidence from the study of Davis et al. (2008) showed that miR-21 mediated the TGF- $\beta$ - and bone morphogenetic protein (BMP)-induced contractile phenotype switch in human SMCs. Meanwhile, miR21 downregulated PDCD4, which in turn acts as a negativefeedback regulator of smooth muscle contractile genes (Davis et al., 2008). These data together indicate that miR-21 regulates SMC contractile function, proliferation, and apoptosis.

We found that miR-21 expression was substantially increased as AAAs developed in both the porcine pancreatic elastase perfusion and AngII infusion AAA models. PTEN, a key negative regulator of the phosphoinositide 3-kinase pathway, was the only target significantly downregulated and was inversely correlated with miR-21 expression during AAA development and progression. Lentiviral overexpression of miR-21 limited AAA growth, which was associated with increased SMC proliferation and decreased levels of PTEN expression and apoptosis in the aortic wall. In contrast, systemic injections of a locked nucleic acid (LNA)-modified antagomir targeting miR-21 diminished the pro-proliferative impact of downregulated PTEN, leading to a marked increase in AAA size. Our in vitro studies also identified the transcription factor NF-кB as a crucial positive regulator of miR-21 expression in vascular cells. Nicotine, IL-6, and AngII were each able to induce miR-21 via the upregulation of NF- $\kappa$ B.

For translational purposes, the utilization of local delivery tools has been discussed previously and is under current investigation by our lab and others (Maegdefessel, 2014). Local delivery into the vasculature and diseased aorta appears feasible by using drug eluting stents and balloons, enabling miRNAbased therapies to avoid off-target effects in the respiratory, renal and cardiovascular system, as well as the liver and the spleen. For miR-21 inhibition, and its effects on SMC proliferation we have utilized an anti-miR-21-eluting stent to effectively prevent experimental in-stent restenosis without significant observable side effects (Wang et al., 2015a). However, to make balloon and/or stent- delivered miRNA modulators a real option for the future, additional obstacles have to taken, including optimal patient selection and timing of the intervention, as well as strategies how to handle disease-related barriers, such as intraluminal thrombi and the varying anatomy of different AAA. In relation to this, the development of novel (ideally patientlike) pre-clinical models of AAA, utilizing large animal models (e.g., landrace pigs and/or Yucatan mini-pigs), which based on their dimension and physiological properties (circulating blood volume, size of the aorta, blood pressure, etc.) are better suited for translational approaches to test novel therapies in aortic diseases.

\section{MIRNAS AND EXTRACELLULAR MATRIX FORMATION}

The aortic wall is composed of three layers: the intima, the media, and the adventitia. Medial SMCs and an arrangement of ECM structural proteins, primarily collagen and elastin, are essential for the maintenance of the structure and function of the aorta. During AA development, the integrity of these layers and protein components are disrupted. Degradation of the ECM is one of the characteristics of AAs, yet the mechanisms underlying this process are incompletely understood. It has been suggested that TGF- $\beta$ signaling plays a key role in ECM dysregulation and AAA development.

Among the miR-15 family members, miR-195 levels were shown to be significantly increased in the aortas of Apo Edeficient mice after AngII infusion. Consistent with the increased levels of miR-195 in dissected human aortas, the direct binding of miR-195 to several ECM transcripts was detected. Based on these findings, Zampetaki et al. (2014) conducted a proteomics analysis of the secretome of murine aortic SMCs after miR-195 manipulation and revealed that miR-195 targets a group of ECM proteins, including collagens, proteoglycans, elastin, and proteins associated with elastic microfibrils. The inhibition of miR-195 in vivo led to higher expression levels of aortic elastin, being related to increases in levels of both MMP-2 and MMP-9.

In human plasma, miR-195 expression was shown to lead to an inverse correlation between the presence of AAAs and aortic diameter (Zampetaki et al., 2014). These data indicated that miR-195 may contribute to the pathogenesis of AAAs via ECM dysregulation.

In addition to miR-195, previous data from our lab has illustrated a crucial role for miR-29b in ECM homeostasis and AAA development (Maegdefessel et al., 2012b). The miR29 family of miRNAs (miR-29a, miR-29b, and miR-29c) have been reported to target various genes that encode ECM proteins involved in fibrotic responses, including several collagen isoforms (e.g., collagen types I and III), fibrillin-1, and elastin (van Rooij et al., 2006). A profibrotic response is usually considered a pathological feature, accompanied by significant malfunctions of affected organs, including the respiratory and renal system, as well as the heart and the liver. However, fibrotic responses and ECM deposition appear essentially beneficial for patients with AAs, based on the fact that one of the hallmarks of AAs is the constant degradation of the ECM.

Our data indicated that miR-29b was the only member of the miR-29 family whose levels were substantially decreased at three different time points during murine AAA development and progression. Anti-miR-29b treatment mainly increased the expression of genes encoding collagen (Col1a1, Col2a1, Col3a1, and Col5a1) and elastin, which accounted for limited aneurysm expansion. In contrast, the overexpression of miR-29b using a 
lentiviral vector led to rapid AAA expansion and an increased rate of aortic rupture. Furthermore, human AAA tissue samples displayed a similar pattern of reduced miR-29b expression with increased collagen gene expression in comparison to tissue samples from non-aneurysmal organ donor controls. Furthermore, cell culture studies identified aortic fibroblasts as the likely cell type mediating the profibrotic effects of miR-29b. Interestingly, TGF- $\beta$, a validated regulator of tissue fibrosis, can repress miR-29b expression, which suggests a protective role of TGF- $\beta$ in limiting AAA development. A more detailed discussion of the miR-29 family in relation to aging and TAAs can be found below.

\section{MIRNAS IN TAAS}

The miR-143/145 cluster is highly expressed in SMCs; it is one of the most studied miRNAs in the regulation of SMC phenotype switching and vascular disease pathogenesis (Boettger et al., 2009). MiR-145 has been repeatedly shown to promote SMC differentiation and to inhibit SMC proliferation (Cheng et al., 2009; Cordes et al., 2009). Tunica media SMCs have been observed to transform from a contractile phenotype to a synthetic phenotype during thoracic aortic dissection (TAD; Lesauskaite et al., 2001). Elia et al. (2009) also found decreased miR-143 and miR-145 expression levels in human AAs, which subsequently induced structural changes in the aorta, due to the incomplete differentiation of SMCs. In addition, Liao et al. (2011) reported that miR143 and miR-145 were downregulated in TAD, which may account for the underdifferentiation of SMCs and aortic remodeling.

Apart from the proinflammatory effects elicited by activated macrophages, miR-181b was also shown to be involved in ECM dysregulation during TAA development and progression. Prominent fragmentation of the elastic lamellae, a key feature of TAAs, was abrogated by the inhibition of miR-181b compared with control animals; increased TIMP3 expression and collagen accumulation were also observed (Di Gregoli et al., 2017).

As mentioned above, miR-29 family members have also been shown to participate in TAA development and progression. Boon et al. (2011) managed to link miRNA regulation to aortic dilatation and aging. The authors discovered that elevated expression levels of miR-29 family members were associated with a profound downregulation of numerous ECM components in the aortas of aged mice, as well as in two experimental models of aortic dilation (i.e., AngII perfusion and Fibulin $4^{\mathrm{R} / \mathrm{R}}$ mice). Consistent with our results in AAAs (Maegdefessel et al., 2012b), LNA-modified antisense oligonucleotide-mediated silencing of miR-29 was found to induce collagen gene isoform expression and inhibit AngII-stimulated dilation of aortas in mice.

In a similar context, Merk and collaborators (Merk et al., 2012) further revealed that miR-29b participates in early aneurysm development in Marfan/Fbn1 $1^{\mathrm{C} 1039 \mathrm{G} /+}$ mice. Blockade of miR$29 \mathrm{~b}$ prevented early aneurysm development, cell apoptosis, and ECM deficiencies in the aortic root. These data suggest that miR29 may represent a novel molecular target to augment matrix synthesis and maintain the structural integrity of the vascular wall.

A study from Jones et al. (2011) identified the role of miR-29a in TAA development. A significant inverse relationship between miR-29a and MMP-2 was identified in clinical TAA specimens, indicating that miR-29a may regulate ECM production by targeting MMP-2 during TAA development.

Recently, a new cluster of miRNAs (miR-17-associated miRNAs) was identified in progressive aortic dilation (Wu et al., 2016). Patients with a bicuspid aortic valve (BAV) are at increased risk for progressive aortic dilation associated with ECM degradation, relating to the increased activity of MMPs. In the heart, MMP activity is regulated via miR-17-enforced repression of TIMP, a mechanism the investigators were able to establish for the ascending aorta as well. MiRNA profiling of samples from dilated sections of ascending aortas indicated significantly increased miR-17 cluster expression levels in less dilated aortic segments compared to severely dilated segments. Both TIMP1 and TIMP-2 were validated as miR-17 targets, and their expression levels were substantially decreased in the less dilated samples. As expected, the subsequent increased activity of MMPs was found to contribute to ECM disruption and aortic dilation. In addition, an miR-17 mimic decreased TIMP-1 and TIMP-2 expression and increased MMP2 activity in SMCs isolated from normal and BAV aortas, whereas the opposite effects were seen with an miR-17 inhibitor, suggesting that the miR-17-TIMPMMP pathway mediates matrix degradation in progressive aortic dilation in BAV-associated AAs.

\section{LONG NON-CODING RNAS}

Long non-coding RNAs (lncRNAs) are generally defined as RNA transcripts with lengths $>200$ nt that do not encode proteins. They are involved in numerous biological events, such as signaling via scaffolding proteins, shaping nuclear architecture, imprinting genomic loci, and regulating enzymatic activity (Engreitz et al., 2016; Figure 1). The aberrant expression or mutation of lncRNA genes has been implicated in various human diseases (Batista and Chang, 2013). However, the functional roles and mechanisms of most lncRNAs remain elusive (Cech and Steitz, 2014).

Particularly in cardiovascular development and diseases, very few lncRNAs have been functionally characterized. Braveheart was the first lncRNA described in the heart, being required for cardiac development (Klattenhoff et al., 2013). Similarly, the lncRNA Fendrr regulates the transcriptional network required for cardiac development via interactions with histone-modifying complexes (polycomb Repressive Complex 2, PRC2 and trithorax group/myeloid/lymphoid or mixed-lineage Leukemia, TrxG/MLL) (Grote et al., 2013). There are other lncRNAs related to the differentiation of human embryonic stem cells, including TERMINATOR, ALIEN, and PUNISHER (Kurian et al., 2015).

During the development of cardiovascular diseases, lncRNAs seem to either serve as potential indicators (biomarkers) or regulators of cell function and disease progression. For instance, Novlnc6 was found to be differentially expressed 
in patients with dilated cardiomyopathy (Ounzain et al., 2015), and Hotair levels were reduced in patients with BAV and related valve calcifications (Carrion et al., 2014). The expression levels of the lncRNAs HIF1A antisense RNA (aHIF), antisense non-coding RNA in the INK4 Locus (ANRIL), KCNQ1 opposite strand/antisense transcript 1 (KCNQ1OT1), myocardial infarction associated transcrip (MIAT), and metastasis associated lung adenocarcinoma transcript 1 (MALAT1) may be associated with acute myocardial infarction(Vausort et al., 2014). MALAT1 regulates EC function and vascular inflammation in patients with diabetes-induced vascular complications (Michalik et al., 2014), while MIAT was identified as a competing endogenous RNA, that forms a feedback loop with VEGF and miR-150-5p and controls EC function in diabetic retinopathies (Yan et al., 2015). The long intergenic non-coding RNA (lincRNA)-p21 was shown to repress proliferation and induce apoptosis of SMCs in atherosclerotic plaques (Wu et al., 2014).

One particular lncRNA, H19, appears to have a universal effect on the cardiovascular system. The downregulation of H19 was shown to promote cell proliferation and inhibit cell apoptosis during late-stage cardiac differentiation by regulating the negative role of miR-19b in Sox6 expression (Han et al., 2016). H19 was also shown to mediate the inhibition of melatonin by inducing the premature senescence of c-kit + cardiac progenitor cells via miR-675 stimulation (Cai et al., 2016). In addition, H19 inhibition was found to decrease human umbilical vein endothelial cells (HUVEC) growth and capillary formation, while the H19-miR-675 axis targets calcium/calmodulin dependent protein kinase II Delta (CaMKII $\delta$ ), thus serving as a negative regulator of cardiac hypertrophy (Liu et al., 2016). H19-derived miR-675 was found to aggravate restenosis by targeting PTEN in VSMCs (Lv et al., 2017). These data indicate that H19 participates in cardiac development and related cardiovascular disease processes. The altered DNA methylation of H19 in calcified aortic valve disease was shown to promote mineralization by silencing NOTCH1 (Hadji et al., 2016). LncRNAs that have been studied for their implications in SMC plasticity and AA development and dilation are summarized in Table 2.

\section{LNCRNAS AND SMOOTH MUSCLE CELL FATE}

The lncRNA ANRIL was identified as a transcript within the chromosome 9p21 locus, in which genetic variants are believed to contribute to the risk of cardiovascular disease (Broadbent et al., 2008). The genomic region (9p21) also contains the cyclindependent kinase Inhibitor 2A (CDKN2A) and CDKN2B genes, which encode for the cell cycle regulators p16 (INK4a), p14 (ARF), and p15 (INK4b). Two independent studies by Congrains et al. (2012) and Motterle et al. (2012) demonstrated that the alleles linked to atherosclerosis-related phenotypes and risk of common carotid artery stenosis were consistently associated with lower expression levels of ANRIL. Knockdown of ANRIL

\begin{tabular}{|c|c|c|c|c|c|}
\hline LncRNAs & Sample studied & Regulation & Related genes & Related Functions & References \\
\hline ANRIL & $\begin{array}{l}\text { human blood, mouse } \\
\text { atherosclerotic plaque, } \\
\text { HAoSMCs }\end{array}$ & $\downarrow$ & $\begin{array}{l}\text { CDKN2A, CDKN2B, } \\
\text { DAB2IP, LRP1, LRPR, } \\
\text { CNTN3 }\end{array}$ & $\begin{array}{l}\text { Influences CDKN2A/B expression } \\
\text { and promotes proliferation of VSMC }\end{array}$ & $\begin{array}{l}\text { Congrains et al., 2012; } \\
\text { Motterle et al., } 2012\end{array}$ \\
\hline RNCR3 & $\begin{array}{l}\text { Human blood, mouse } \\
\text { atherosclerotic plaque, } \\
\text { HAoSMCs, ECs }\end{array}$ & $\uparrow$ & KLF-2, miR-185-5p & $\begin{array}{l}\text { Acts as a ceRNAs, decreases EC and } \\
\text { VSMC proliferation }\end{array}$ & Shan et al., 2016 \\
\hline $\mathrm{H} 19$ & $\begin{array}{l}\text { Balloon-injured artery, } \\
\text { HAoSMCs }\end{array}$ & $\uparrow$ & miR-675 & $\begin{array}{l}\text { Generates miRNA, Promotes VSMC } \\
\text { proliferation }\end{array}$ & Lv et al., 2017 \\
\hline Lnc-Ang362 & mVSMCs & $\uparrow$ & miR-221/222 & $\begin{array}{l}\text { Produces miRs and promotes VSMC } \\
\text { proliferation }\end{array}$ & Leung et al., 2016 \\
\hline SENCR & HAoSMCs & - & FLI1 & Inhibits migration of VSMC & Bell et al., 2014 \\
\hline Lnc-GAS5 & $\begin{array}{l}\text { mouse ocular vessels, SHR rat } \\
\text { artery, HUVECs, HAoSMCs }\end{array}$ & $\downarrow$ & $\beta$-Catenin & $\begin{array}{l}\text { Regulates ECs activation and } \\
\text { proliferation, VSMC phenotypic } \\
\text { conversion, and EC-VSMC } \\
\text { communication }\end{array}$ & Wang et al., 2016 \\
\hline Lnc-MEG3 & HAoSMCs & - & p53, MMP-2 & $\begin{array}{l}\text { Promotes proliferation and migration } \\
\text { and decrease apoptosis of VSMC }\end{array}$ & Liu et al., 2017 \\
\hline MYOSLID & HCASMC & - & $\begin{array}{l}\text { MYOCD/serum response } \\
\text { factor and TGF- } \beta / S M A D\end{array}$ & Regulates VSMC phenotype & Zhao et al., 2016 \\
\hline HIF1A-AS1 & $\begin{array}{l}\text { Human TAAs serum, } \\
\text { HAoSMCs }\end{array}$ & - & BRG1, Casp3/8, BCL2 & $\begin{array}{l}\text { Inhibits proliferation and induced } \\
\text { apoptosis of VSMC }\end{array}$ & $\begin{array}{l}\text { He et al., 2015; Wang } \\
\text { et al., 2015c }\end{array}$ \\
\hline
\end{tabular}

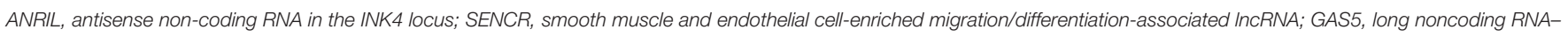

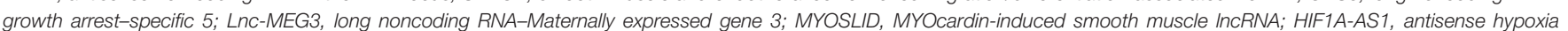

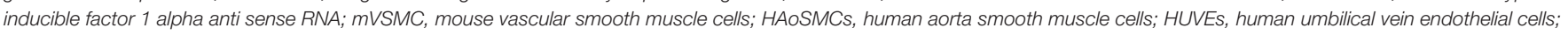

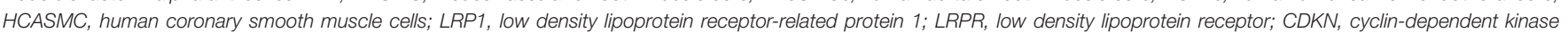

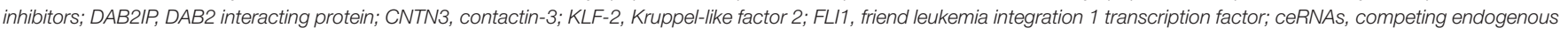
RNAs; BCL2, B-cell lymphoma 2; BRG1, Brahma-related gene 1; TGF- $\beta$, transforming growth factor- $\beta$; SMAD, mothers against decapentaplegic homolog. 
in SMCs was shown to cause significant variations in the expression of CDKN2A/B and reduced cell growth, suggesting that ANRIL may have pro-proliferation effects on SMCs. Leeper and colleagues have shown that loss of CDKN2B is crucial for aneurysm development via promoting p53-dependent SMC apoptosis (Leeper et al., 2013). The role of ANRIL itself in AA development needs to be investigated further.

LncRNA-RNCR3 is another lncRNA that has been linked to atherosclerosis-related vascular dysfunction (Shan et al., 2016). RNCR3 expression is significantly upregulated in mouse and human aortic atherosclerotic lesions, and inhibition of RNCR3 was shown to be sufficient to accelerate the development of atherosclerosis, aggravate hypercholesterolemia and inflammatory factor releases, and decrease EC and VSMC proliferation. Mechanistically, RNCR3 acts as a competing endogenous RNA (ceRNA) and forms a feedback loop with Kruppel-like factor 2 and miR-185-5p to regulate cell function. This study illuminated one of the most common mechanisms by which lncRNAs can act as ceRNAs to decrease the targeting concentration of miRNA, ultimately resulting in the derepression of other mRNAs with common miRNA response elements (Tay et al., 2014).

Another proposed mechanism of action for lncRNAs describes how these molecules serve as hosts for miRNA transcription. Lv et al. (2017) found that lncRNA H19 and H19-derived miR-675 are overexpressed in the neointima of balloon-injured arteries. In principal, they were able to show that lncRNA H19 promoted the proliferation of SMCs in an miR-675/PTEN-dependent manner. Similar roles were detected for the lnc-Ang362, which is substantially increased in response to AngII treatment (Leung et al., 2016). Knockdown of lnc-Ang362 reduces the expression of miR-222 and miR221, suggesting its function as a miRNA host transcript. In addition, a reduction in the transcript levels of lnc-Ang362 was associated with a decrease in cell proliferation, suggesting that it plays a role in cell growth. These data evoke tremendous interest, considering that one of the most popular murine models of AAA development is AngII infusion in Apo $E^{-/-}$ mice.

Smooth muscle and endothelial cell enriched migration/differentiation-associated long non-coding RNA (SENCR) was identified from the RNA sequencing of human coronary artery SMCs (Bell et al., 2014). SENCR is transcribed in the cytoplasm from the $5^{\prime}$ end of the friend leukemia integration 1 (FLI1) gene and exists as two splice variants. Experimental knockdown of SENCR has been shown to result in the decreased expression of myocardin and numerous smooth muscle contractile genes, and the increased expression of a number of promigratory genes. Results from loss-of-function studies support the role of Sencr as an inhibitor of SMC migration. Whether this property of phenotype regulation plays a role in AA development awaits further investigation.

In terms of SMC phenotypic switching, lncRNA-growth arrest-specific 5 (GAS5) was reported to be involved in hypertension-related vascular remodeling via changes in endothelial activation and proliferation, SMC phenotype

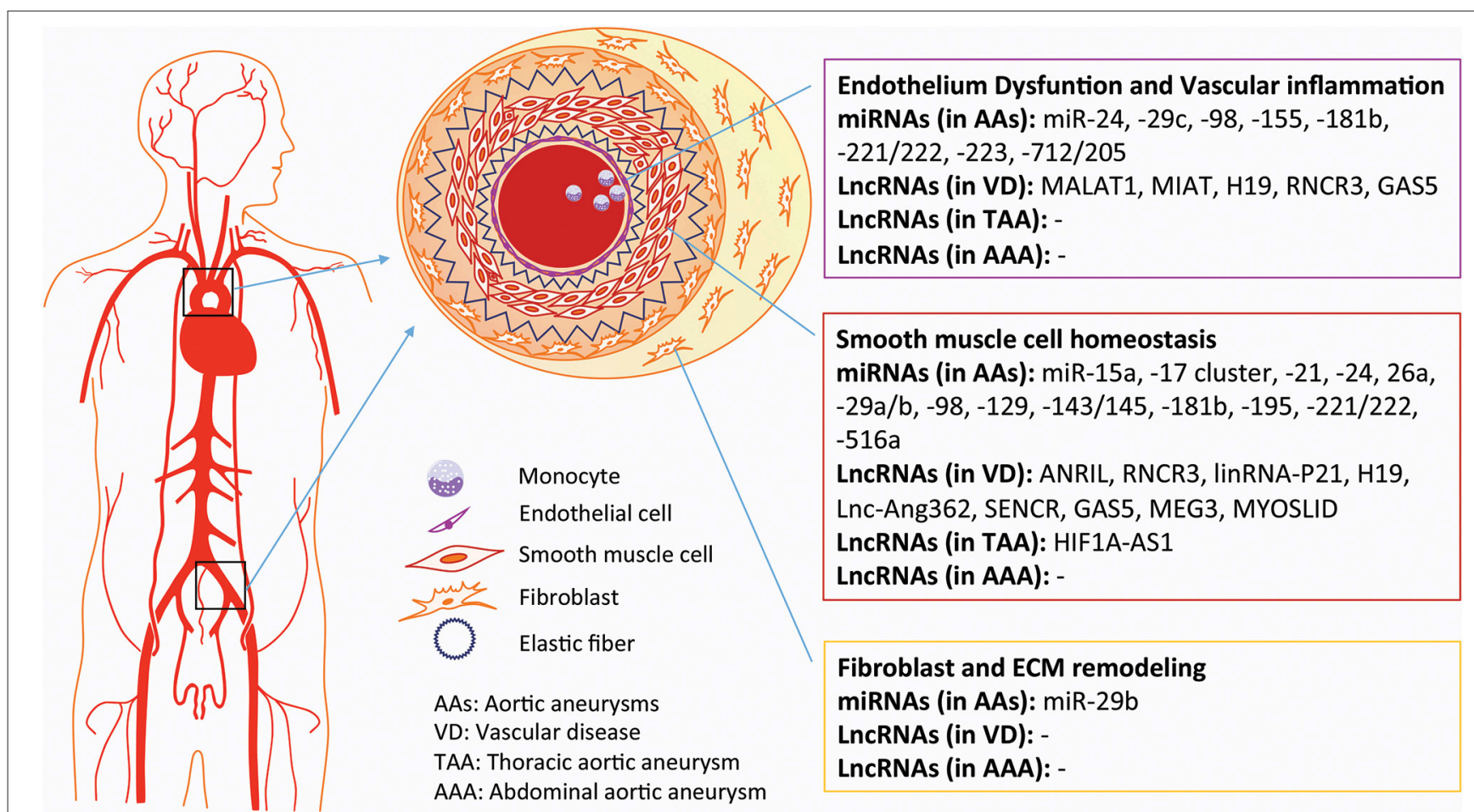

FIGURE 2 | Non-coding RNAs involved in vascular disease and aortic aneurysms. 
conversion, and EC-VSMC communication, primarily through $\beta$-catenin signaling (Wang et al., 2016).

Recently, Zhao et al. (2016) described a novel lncRNA, named myocardin-induced smooth muscle lncRNA (MYOSLID), which is related to SMC phenotype regulation. MYOSLID, a direct transcriptional target of both the $\mathrm{MYOCD} /$ serum response factor (SRF) and TGF- $\beta /$ SMAD pathways, promotes SMC differentiation and inhibits SMC proliferation. Depletion of MYOSLID in SMCs was shown to not only disrupt actin stress fiber formation and block nuclear translocation of MYOCDrelated transcription factor A (MKL1), but was also found to abrogate TGF- $\beta 1$-induced SMAD2 phosphorylation. These data suggest that MYOSLID may play a role in AA development via the crosstalk between the dysregulation of the VSMC phenotype and TGF- $\beta$ signaling.

\section{LNCRNAS AND AAS}

HIF1 alpha-antisense RNA 1 (HIF1A-AS1) was the first reported lncRNA that was found to play a role in TAA pathogenesis (Wang et al., 2015c). The expression of HIF1A-AS1 was shown to be regulated by Brahma-related gene 1, whose levels are elevated in TAAs. Suppression of HIF1A-AS1 was found to result in reduced apoptosis and increased proliferation of VSMCs. Furthermore, the expression of HIF1a-AS1 was reported to be significantly increased in sera from TAA patients (He et al., 2015). Knockdown of HIF1A-AS1 was shown to decrease the expression of caspase3 and caspase-8, increase the expression of BCL2, and attenuate palmitic acid (PA)-induced cell apoptosis in SMCs. Loeys-Dietz syndrome (LDS) is an autosomal dominant genetic connective tissue disorder, and most LDS patients will commonly develop an aneurysm in the aortic root. Yu et al. (2015) found that the lncRNA AK056155 was up-regulated in LDS specimen, which correlated with an activation of the AKT/PI3K and TGF- $\beta 1$ signaling.

Currently, there are no available publications of the roles of lncRNAs in AAAs. One paper from Falak et al. (2014) suggested that a putative lincRNA within the linkage region of protease inhibitor 15 (Pi15), a candidate gene marker for the risk of abdominal aortic internal elastic laminal ruptures in rats, may be involved in the regulation of Pi15 expression, providing some clues about the roles of lncRNAs in the initiation of human AAAs.

\section{SUMMARY AND PERSPECTIVE}

Today, undiscovered asymptomatic AAs are still considered to be ticking time bombs, owing to their incredibly high rates of

\section{REFERENCES}

Ailawadi, G., Moehle, C. W., Pei, H., Walton, S. P., Yang, Z., Kron, I. L. et al. (2009). Smooth muscle phenotypic modulation is an early event in aortic aneurysms. J. Thorac. Cardiovasc. Surg. 138, 1392-1399. doi: 10.1016/j.jtcvs.2009.07.075

Bartel, D. P. (2004). MicroRNAs, genomics, biogenesis, mechanism, and function. Cell 116, 281-297. doi: 10.1016/S0092-8674(04)00045-5

Bartel, D. P. (2009). MicroRNAs, target recognition and regulatory functions. Cell 136, 215-233. doi: 10.1016/j.cell.2009.01.002 mortality $(\sim 80 \%)$ when ruptured. Current clinical management of AAs, based only on size, is not satisfactory. Thus, extraordinary efforts have been launched to determine the pathophysiological characteristics and molecular events of the diseased aorta. Increasing evidence suggests that ncRNAs play crucial roles throughout AA development and might serve as therapeutic targets (Figure 2). As mentioned above, the pathogenesis and molecular mechanisms of TAAs and AAAs are distinguishable, suggesting that the roles of ncRNAs will be as well. As the field of miRNAs gradually matures, some promising candidates, such as miR-122, miR-21, miR-15, and miR-34 (Janssen et al., 2013; Christopher et al., 2016), may be further investigated in preclinical and clinical trials. The combined modulation of miRNAs in specific cell subtypes, like increasing SMC survival by miR-2 1 and inducing adventitial fibrosis by inbibiting miR-29b, would be worthwhile investments in AAA therapy.

The field of lncRNAs is still in its infancy and faces many challenges. First, the conservation of lncRNAs among species is not as high as that of miRNAs, and humanized models or organoid cultures will be necessary to study primatespecific lncRNAs. Second, mechanisms of action of lncRNAs are complicated and may be organ- or cell-specific. Third, the molecular mechanisms may be broadly diverse, based on the subcellular localization of lncRNAs and the existence of disparate transcriptional variants. Single-cell profiling and single-molecule imaging techniques are crucial to the detailed identification of components of these processes and machineries. Finally, a more efficient and specific delivery system is required for the modulation of lncRNAs in vivo to minimize off-targets and translate findings into clinical practice.

\section{AUTHOR CONTRIBUTIONS}

Both authors listed contributed to this manuscript by conceptually designing and drafting the manuscript. Both authors have seen and approved the article for submission to Frontiers in Physiology.

\section{ACKNOWLEDGMENTS}

Research in the Maegdefessel laboratory on non-coding RNAs in cardiovascular disease is supported by the Swedish Heart-Lung-Foundation (20120615, 20130664, and 20140186), the Ragnar Söderberg Foundation (M55/14), the Swedish Research Council (2015-03140), the European Research Council (ERC-StG NORVAS), and a DZHK Junior Research Group (JRG_LM_MRI).

Batista, P. J., and Chang, H. Y. (2013). Long noncoding RNAs, cellular address codes in development and disease. Cell 152, 1298-1307. doi: 10.1016/j.cell.2013.02.012

Bell, R. D., Long, X., Lin, M., Bergmann, J. H., Nanda, V. Cowan, S. L., et al. (2014). Identification and initial functional characterization of a human vascular cellenriched long noncoding RNA. Arterioscler Thromb. Vasc. Biol. 34, 1249-1259. doi: 10.1161/ATVBAHA.114.303240

Biros, E., Moran, C. S., Wang, Y., Walker, P. J., Cardinal, J., and Golledge, J. (2014). microRNA profiling in patients with abdominal aortic aneurysms, 
the significance of miR-155. Clin. Sci. 126, 795-803. doi: 10.1042/CS201 30599

Boettger, T., Beetz, N., Kostin, S., Schneider, J., Kruger, M., Hein, L., et al. (2009). Acquisition of the contractile phenotype by murine arterial smooth muscle cells depends on the Mir143/145 gene cluster. J. Clin. Invest. 119, 2634-2647. doi: $10.1172 / \mathrm{JCI} 38864$

Boon, R. A., Seeger, T., Heydt, S., Fischer, A., Hergenreider, E., Vinciguerra, M., et al. (2011). MicroRNA-29 in aortic dilation, implications for aneurysm formation. Circ. Res. 109, 1115-1119. doi: 10.1161/CIRCRESAHA.111.255737

Broadbent, H. M., Peden, J. F., Lorkowski, S., Goel, A., Ongen, H., Green, F., et al. (2008). Susceptibility to coronary artery disease and diabetes is encoded by distinct, tightly linked SNPs in the ANRIL locus on chromosome 9p. Hum. Mol. Genet. 17, 806-814. doi: 10.1093/hmg/ddm352

Busch, A., Busch, M., Scholz, C. J., Kellersmann, R., Otto, C., Chernogubova, E., et al. (2016). Aneurysm miRNA Signature Differs, Depending on Disease Localization and Morphology. Int. J. Mol. Sci. 17. doi: 10.3390/ijms17010081

Cai, B., Ma, W., Bi, C., Yang, F., Zhang, L., Han, Z., et al. (2016). Long noncoding RNA H19 mediates melatonin inhibition of premature senescence of c-kit $(+)$ cardiac progenitor cells by promoting miR-675. J. Pineal Res. 61, 82-95. doi: $10.1111 /$ jpi.12331

Carrion, K., Dyo, J., Patel, V., Sasik, R., Mohamed, S. A., Hardiman, G., et al. (2014). The long non-coding HOTAIR is modulated by cyclic stretch and WNT/betaCATENIN in human aortic valve cells and is a novel repressor of calcification genes. PLoS ONE 9:e96577. doi: 10.1371/journal.pone.0096577

Cech, T. R., and Steitz, J. A. (2014). The noncoding RNA revolution-trashing old rules to forge new ones. Cell 157, 77-94. doi: 10.1016/j.cell.2014.03.008

Cheng, Y., Liu, X., Yang, J., Lin, Y., Xu, D. Z., Lu, Q., et al. (2009). MicroRNA-145, a novel smooth muscle cell phenotypic marker and modulator, controls vascular neointimal lesion formation. Circ. Res. 105, 158-166. doi: 10.1161/CIRCRESAHA.109.197517

Christopher, A. F., Kaur, R. P., Kaur, G., Kaur, A., Gupta, V., and Bansal, P. (2016). MicroRNA therapeutics, Discovering novel targets and developing specific therapy. Perspect. Clin. Res. 7, 68-74. doi: 10.4103/2229-3485.179431

Congrains, A., Kamide, K., Oguro, R., Yasuda, O., Miyata, K., Yamamoto, E., et al. (2012). Genetic variants at the 9p21 locus contribute to atherosclerosis through modulation of ANRIL and CDKN2A/B. Atherosclerosis 220, 449-455. doi: 10.1016/j.atherosclerosis.2011.11.017

Cordes, K. R., Sheehy, N. T., White, M. P., Berry, E. C., Morton, S. U., Muth, A. N., et al. (2009). miR-145 and miR-143 regulate smooth muscle cell fate and plasticity. Nature 460, 705-710. doi: 10.1038/nature08195

Davis, B. N., Hilyard, A. C., Lagna, G., and Hata, A. (2008). SMAD proteins control DROSHA-mediated microRNA maturation. Nature 454, 56-61. doi: $10.1038 /$ nature 07086

Davis, B. N., Hilyard, A. C., Nguyen, P. H., Lagna, G., and Hata, A. (2009). Induction of microRNA-221 by platelet-derived growth factor signaling is critical for modulation of vascular smooth muscle phenotype. J. Biol. Chem. 284, 3728-3738. doi: 10.1074/jbc.M808788200

Di Gregoli, K., Mohamad Anuar, N. N., Bianco, R., White, S. J., Newby, A. C., Muth, A. N., et al. (2017). MicroRNA-181b Controls Atherosclerosis and Aneurysms Through Regulation of TIMP-3 and Elastin. Circ. Res. 120, 49-65. doi: 10.1161/CIRCRESAHA.116.309321

Djuranovic, S., Nahvi, A., and Green, R. (2011). A parsimonious model for gene regulation by miRNAs. Science 331, 550-553. doi: 10.1126/science.11 91138

Ebert, M. S., and Sharp, P. A. (2012). Roles for microRNAs in conferring robustness to biological processes. Cell 149, 515-524. doi: 10.1016/j.cell.2012.04.005

Elefteriades, J. A., Sang, A., Kuzmik, G., and Hornick, M. (2015). Guilt by association, paradigm for detecting a silent killer (thoracic aortic aneurysm). OpenHeart 2:e00169. doi: 10.1136/openhrt-2014-000169

Elia, L., Quintavalle, M., Zhang, J., Contu, R., Cossu, L., Latronico, M. V., et al. (2009). The knockout of miR-143 and -145 alters smooth muscle cell maintenance and vascular homeostasis in mice, correlates with human disease. Cell Death Differ. 16, 1590-1598. doi: 10.1038/cdd.2009.153

Engreitz, J. M., Ollikainen, N., and Guttman, M. (2016). Long non-coding RNAs, spatial amplifiers that control nuclear structure and gene expression. Nat. Rev. Mol. Cell Biol. 17, 756-770. doi: 10.1038/nrm.2016.126

Esteller, M. (2011). Non-coding RNAs in human disease. Nat. Rev. Genet. 12, 861-874. doi: $10.1038 / \operatorname{nrg} 3074$
Falak, S., Schafer, S., Baud, A., Hummel, O., Schulz, H., Gauguier, D., et al. (2014). Protease inhibitor 15, a candidate gene for abdominal aortic internal elastic lamina ruptures in the rat. Physiol. Genomics 46, 418-428. doi: 10.1152/physiolgenomics.00004.2014

Fiedler, J., Jazbutyte, V., Kirchmaier, B. C., Gupta, S. K., Lorenzen, J., Hartmann, D., et al. (2011). MicroRNA-24 regulates vascularity after myocardial infarction. Circulation 124, 720-730. doi: 10.1161/CIRCULATIONAHA.111.039008

Fu, X. D. (2014). Non-coding RNA, a new frontier in regulatory biology. Natl. Sci. Rev. 1, 190-204. doi: 10.1093/nsr/nwu008

Gao, P., Si, J., Yang, B., and Yu, J. (2017). Upregulation of MicroRNA15a Contributes to Pathogenesis of Abdominal Aortic Aneurysm (AAA) by Modulating the Expression of Cyclin-Dependent Kinase Inhibitor 2B (CDKN2B). Med. Sci. Monit. 23, 881-888. doi: 10.12659/MSM.898233

Geng, S., Chen, K., Yuan, R., Peng, L., Maitra, U., Diao, N., et al. (2016). The persistence of low-grade inflammatory monocytes contributes to aggravated atherosclerosis. Nat. Commun. 7:13436. doi: 10.1038/ncomms13436

Golledge, J., Muller, J., Daugherty, A., and Norman, P. (2006). Abdominal aortic aneurysm, pathogenesis and implications for management. Arterioscler. Thromb. Vasc. Biol. 26, 2605-2613. doi: 10.1161/01.ATV.0000245819.32762.cb

Golledge, J., and Norman, P. E. (2011). Current status of medical management for abdominal aortic aneurysm. Atherosclerosis 217, 57-63. doi: 10.1016/j.atherosclerosis.2011.03.006

Grote, P., Wittler, L., Hendrix, D., Koch, F., Wahrisch, S., Beisaw, A., et al. (2013). The tissue-specific lncRNA Fendrr is an essential regulator of heart and body wall development in the mouse. Dev. Cell 24, 206-214. doi: 10.1016/j.devcel.2012.12.012

Guo, D. C., Papke, C. L., He, R., and Milewicz, D. M. (2006). Pathogenesis of thoracic and abdominal aortic aneurysms. Ann. N. Y. Acad. Sci. 1085, 339-352. doi: 10.1196/annals.1383.013

Habashi, J. P., Judge, D. P., Holm, T. M., Cohn, R. D., Loeys, B. L., Cooper, T. K., et al. (2006). Losartan, an AT1 antagonist, prevents aortic aneurysm in a mouse model of Marfan syndrome. Science 312, 117-121. doi: $10.1126 /$ science. 1124287

Hadji, F., Boulanger, M. C., Guay, S. P., Gaudreault, N., Amellah, S., Mkannez, G., et al. (2016). Altered DNA Methylation of Long Noncoding RNA H19 in Calcific Aortic Valve Disease Promotes Mineralization by Silencing NOTCH1. Circulation 134, 1848-1862. doi: 10.1161/CIRCULATIONAHA.116.023116

Han, Y., Xu, H., Cheng, J., Zhang, Y., Gao, C., et al. (2016). Downregulation of long non-coding RNA H19 promotes P19CL6 cells proliferation and inhibits apoptosis during late-stage cardiac differentiation via miR-19b-modulated Sox6. Cell Biosci. 6:58. doi: 10.1186/s13578-016-0123-5

Hatziapostolou, M., Polytarchou, C., Aggelidou, E., Drakaki, A., Poultsides, G. A., Jaeger, S. A., et al. (2011). An HNF $4 \alpha$-miRNA inflammatory feedback circuit regulates hepatocellular oncogenesis. Cell 147, 1233-1247. doi: 10.1016/j.cell.2011.10.043

He, Q., Tan, J., Yu, B., Shi, W., and Liang, K. (2015). Long noncoding RNA HIF1AAS1A reduces apoptosis of vascular smooth muscle cells, implications for the pathogenesis of thoracoabdominal aorta aneurysm. Pharmazie 70, 310-315.

Henderson, E. L., Geng, Y. J., Sukhova, G. K., Whittemore, A. D., Knox, J., and Libby, P. (1999). Death of smooth muscle cells and expression of mediators of apoptosis by $\mathrm{T}$ lymphocytes in human abdominal aortic aneurysms. Circulation 99, 96-104. doi: 10.1161/01.CIR.99.1.96

Holm, T. M., Habashi, J. P., Doyle, J. J., Bedja, D., Chen, Y., van Erp, C., et al. (2011). Noncanonical TGFbeta signaling contributes to aortic aneurysm progression in Marfan syndrome mice. Science 332, 358-361. doi: 10.1126/science.1192149

Horita, H. N., Simpson, P. A., Ostriker, A., Furgeson, S., Van Putten, V., Weiser-Evans, M. C., et al. (2011). Serum response factor regulates expression of phosphatase and tensin homolog through a microRNA network in vascular smooth muscle cells. Arterioscler. Thromb. Vasc. Biol. 31, 2909-2919. doi: 10.1161/ATVBAHA.111.233585

Hutvagner, G., and Zamore, P. D. (2002). A microRNA in a multiple-turnover RNAi enzyme complex. Science 297, 2056-2060. doi: 10.1126/science.1073827

Isselbacher, E. M., Lino Cardenas, C. L., and Lindsay, M. E. (2016). Hereditary Influence in Thoracic Aortic Aneurysm and Dissection. Circulation 133, 2516-2528. doi: 10.1161/CIRCULATIONAHA.116.009762

Janssen, H. L., Reesink, H. W., Lawitz, E. J., Zeuzem, S., Rodriguez-Torres, M., Patel, K., et al. (2013). Treatment of HCV infection by targeting microRNA. $N$. Engl. J. Med. 368, 1685-1694. doi: 10.1056/NEJMoa1209026 
Ji, R., Cheng, Y., Yue, J., Yang, J., Liu, X., Chen, H., et al. (2007). MicroRNA expression signature and antisense-mediated depletion reveal an essential role of MicroRNA in vascular neointimal lesion formation. Circ. Res. 100, 1579-1588. doi: 10.1161/CIRCRESAHA.106.141986

Jiao, T., Yao, Y., Zhang, B., Hao, D. C., Sun, Q. F., Li, J. B., et al. (2017). Role of MicroRNA-103a Targeting ADAM10 in Abdominal Aortic Aneurysm. Biomed. Res. Int. 2017:9645874. doi: 10.1155/2017/9645874

Jingjing, Z., Nan, Z., Wei, W., Qinghe, G., Weijuan, W., Peng, W., et al. (2017). MicroRNA-24 Modulates Staphylococcus aureus-Induced Macrophage Polarization by Suppressing CHI3L1. Inflammation 40, 995-1005. doi: 10.1007/s10753-017-0543-3

Jones, J. A., Stroud, R. E., O'Quinn, E. C., Black, L. E., Barth, J. L., Elefteriades, J. A., et al. (2011). Selective microRNA suppression in human thoracic aneurysms, relationship of miR-29a to aortic size and proteolytic induction. Circ. Cardiovasc. Genet. 4, 605-613. doi: 10.1161/CIRCGENETICS.111. 960419

Kanematsu, Y., Kanematsu, M., Kurihara, C., Tada, Y., Tsou, T. L., van Rooijen, N., et al. (2011). Critical roles of macrophages in the formation of intracranial aneurysm. Stroke 42, 173-178. doi: 10.1161/STROKEAHA.110.590976

Kent, K. C. (2014). Clinical practice. Abdominal aortic aneurysms. N. Engl. J. Med. 371, 2101-2108. doi: 10.1056/NEJMcp1401430

Kim, C. W., Kumar, S., Son, D. J., Jang, I. H., Griendling, K. K., and Jo, H. (2014). Prevention of abdominal aortic aneurysm by anti-microRNA-712 or anti-microRNA-205 in angiotensin II-infused mice. Arterioscler. Thromb. Vasc. Biol. 34, 1412-1421. doi: 10.1161/ATVBAHA.113.303134

Kin, K., Miyagawa, S., Fukushima, S., Shirakawa, Y., Torikai, K., Shimamura, K., et al. (2012). Tissue- and plasma-specific MicroRNA signatures for atherosclerotic abdominal aortic aneurysm. J. Am. Heart Assoc. 1:e000745. doi: 10.1161/jaha.112.000745

Klattenhoff, C. A., Scheuermann, J. C., Surface, L. E., Bradley, R. K., Fields, P. A., Steinhauser, M. L., et al. (2013). Braveheart, a long noncoding RNA required for cardiovascular lineage commitment. Cell 152, 570-583. doi: 10.1016/j.cell.2013. 01.003

Kurian, L., Aguirre, A., Sancho-Martinez, I., Benner, C., Hishida, T., et al. (2015). Identification of novel long noncoding RNAs underlying vertebrate cardiovascular development. Circulation 131, 1278-1290. doi: 10.1161/CIRCULATIONAHA.114.013303

Lee, H. J., Yi, J. S., Lee, H. J., Lee, I. W., Park, K. C., and Yang, J. H. (2013). Dysregulated expression profiles of MicroRNAs of experimentally induced cerebral aneurysms in rats. J. Korean Neurosurg. Soc. 53, 72-76. doi: 10.3340/jkns.2013.53.2.72

Lee, Y., Ahn, C., Han, J., Choi, H., Kim, J., Yim, J., et al. (2003). The nuclear RNase III Drosha initiates microRNA processing. Nature 425, 415-419. doi: 10.1038/nature01957

Lee, Y., Jeon, K., Lee, J. T., Kim, S., and Kim, V. N. (2002). MicroRNA maturation, stepwise processing and subcellular localization. EMBO J. 21, 4663-4670. doi: $10.1093 /$ emboj/cdf476

Leeper, N. J., Raiesdana, A., Kojima, Y., Chun, H. J., Azuma, J., Maegdefessel, L., et al. (2011). MicroRNA-26a is a novel regulator of vascular smooth muscle cell function. J. Cell. Physiol. 226, 1035-1043. doi: 10.1002/jcp.22422

Leeper, N. J., Raiesdana, A., Kojima, Y., Kundu, R. K., Cheng, H., Maegdefessel, L., et al. (2013). Loss of CDKN2B promotes p53-dependent smooth muscle cell apoptosis and aneurysm formation. Arterioscler. Thromb. Vasc. Biol. 33, e1-e10. doi: 10.1161/ATVBAHA.112.300399

Lesauskaite, V., Tanganelli, P., Sassi, C., Neri, E., Diciolla, F., Ivanoviene, L., et al. (2001). Smooth muscle cells of the media in the dilatative pathology of ascending thoracic aorta, morphology, immunoreactivity for osteopontin, matrix metalloproteinases, and their inhibitors. Hum. Pathol. 32, 1003-1011. doi: 10.1053/hupa.2001.27107

Leung, A., Stapleton, K., and Natarajan, R. (2016). Functional Long Non-coding RNAs in Vascular Smooth Muscle Cells. Curr. Top. Microbiol. Immunol. 394, 127-141. doi: 10.1007/82_2015_441

Li, X., Zhao, G., Zhang, J., Duan, Z., and Xin, S. (2013). Prevalence and trends of the abdominal aortic aneurysms epidemic in general population-a meta-analysis. PLoS ONE 8:e81260. doi: 10.1371/journal.pone.0081260

Liao, M., Zou, S., Weng, J., Hou, L., Yang, L., Zhao, Z., et al. (2011). A microRNA profile comparison between thoracic aortic dissection and normal thoracic aorta indicates the potential role of microRNAs in contributing to thoracic aortic dissection pathogenesis. J. Vasc. Surg. 53, 1341-1349 e3. doi: 10.1016/j.jvs.2010.11.113

Licholai, S., Szczeklik, W., and Sanak, M. (2016). miR-29c-3p is an effective biomarker of abdominal aortic aneurysm in patients undergoing elective surgery. Microrna 5, 124-131. doi: 10.2174/2211536605666160901103754

Lindsay, M. E., and Dietz, H. C. (2011). Lessons on the pathogenesis of aneurysm from heritable conditions. Nature 473, 308-316. doi: 10.1038/nature10145

Liu, L., An, X., Li, Z., Song, Y., Li, L., Zuo, S., et al. (2016). The H19 long noncoding RNA is a novel negative regulator of cardiomyocyte hypertrophy. Cardiovasc. Res. 111, 56-65. doi: 10.1093/cvr/cvw078

Liu, W., Liu, X., Luo, M., Liu, X., Luo, Q., Tao, H., et al. (2017). dNK derived IFN-gamma mediates VSMC migration and apoptosis via the induction of LncRNA MEG3, A role in uterovascular transformation. Placenta 50, 32-39. doi: 10.1016/j.placenta.2016.12.023

Liu, X., Cheng, Y., Yang, J., Krall, T. J., Huo, Y., and Zhang, C. (2010). An essential role of PDCD4 in vascular smooth muscle cell apoptosis and proliferation, implications for vascular disease. Am. J. Physiol. Cell Physiol. 298, C1481C1488. doi: 10.1152/ajpcell.00413.2009

Liu, X., Cheng, Y., Yang, J., Xu, L., and Zhang, C. (2012). Cell-specific effects of miR-221/222 in vessels, molecular mechanism and therapeutic application. $J$. Mol. Cell. Cardiol. 52, 245-255. doi: 10.1016/j.yjmcc.2011.11.008

Lloyd-Jones, D., Adams, R., Carnethon, M., De Simone, G., Ferguson, T. B., Flegal, K., et al. (2009). Heart disease and stroke statistics2009 update, a report from the American Heart Association Statistics Committee and Stroke Statistics Subcommittee. Circulation 119, 480-486. doi: 10.1161/CIRCULATIONAHA.108.191259

Lv, J., Wang, L., Zhang, J., Lin, R., Wang, L., Sun, W., et al. (2017). Long noncoding RNA H19-derived miR-675 aggravates restenosis by targeting PTEN. Biochem. Biophys. Res. Commun. doi: 10.1016/j.bbrc.2017.01.011. [Epub ahead of print].

Maegdefessel, L. (2014). The emerging role of microRNAs in cardiovascular disease. J. Intern. Med. 276, 633-644. doi: 10.1111/joim.12298

Maegdefessel, L., Azuma, J., Toh, R., Deng, A., Merk, D. R., Raiesdana, A., et al. (2012a). MicroRNA-21 blocks abdominal aortic aneurysm development and nicotine-augmented expansion. Sci. Transl. Med. 4:122ra22. doi: 10.1126/scitranslmed.3003441

Maegdefessel, L., Azuma, J., Toh, R., Merk, D. R., Deng, A., Chin, J. T., et al. (2012b). Inhibition of microRNA-29b reduces murine abdominal aortic aneurysm development. J. Clin. Invest. 122, 497-506. doi: 10.1172/JCI61598

Maegdefessel, L., Spin, J. M., Adam, M., Raaz, U., Toh, R., Nakagami, F., et al. (2013). Micromanaging abdominal aortic aneurysms. Int. J. Mol. Sci. 14, 14374-14394. doi: 10.3390/ijms140714374

Maegdefessel, L., Spin, J. M., Raaz, U., Eken, S. M., Toh, R., et al. (2014). miR-24 limits aortic vascular inflammation and murine abdominal aneurysm development. Nat. Commun. 5:5214. doi: 10.1038/ncomms6214

Mendell, J. T., and Olson, E. N. (2012). MicroRNAs in stress signaling and human disease. Cell 148, 1172-1187. doi: 10.1016/j.cell.2012.02.005

Merk, D. R., Chin, J. T., Dake, B. A., Maegdefessel, L., Miller, M. O., et al. (2012). miR-29b participates in early aneurysm development in Marfan syndrome. Circ. Res. 110, 312-324. doi: 10.1161/CIRCRESAHA.111.253740

Michalik, K. M., You, X., Manavski, Y., Doddaballapur, A., Zornig, M., et al. (2014). Long noncoding RNA MALAT1 regulates endothelial cell function and vessel growth. Circ. Res. 114, 1389-1397. doi: 10.1161/CIRCRESAHA.114.303265

Milewicz, D. M., Guo, D. C., Tran-Fadulu, V., Lafont, A. L., Papke, C. L., Inamoto, S., et al. (2008). Genetic basis of thoracic aortic aneurysms and dissections, focus on smooth muscle cell contractile dysfunction. Annu. Rev. Genomics Hum. Genet. 9, 283-302. doi: 10.1146/annurev.genom.8.080706.092303

Motterle, A., Pu, X., Wood, H., Xiao, Q., Gor, S., Ng, F. L., et al. (2012). Functional analyses of coronary artery disease associated variation on chromosome 9p21 in vascular smooth muscle cells. Hum. Mol. Genet. 21, 4021-4029. doi: $10.1093 / \mathrm{hmg} / \mathrm{dds} 224$

Neptune, E. R., Frischmeyer, P. A., Arking, D. E., Myers, L., Bunton, T. E., Gayraud, B., et al. (2003). Dysregulation of TGF-beta activation contributes to pathogenesis in Marfan syndrome. Nat. Genet. 33, 407-411. doi: $10.1038 / n g 1116$

Ounzain, S., Micheletti, R., Beckmann, T., Schroen, B., Alexanian, M., Pezzuto, I., et al. (2015). Genome-wide profiling of the cardiac transcriptome after myocardial infarction identifies novel heart-specific long non-coding RNAs. Eur. Heart J. 36, 353-368a. doi: 10.1093/eurheartj/ehu180 
Pua, H. H., Steiner, D. F., Patel, S., Gonzalez, J. R., Ortiz-Carpena, J. F., Kageyama, R., et al. (2016). MicroRNAs 24 and 27 suppress allergic inflammation and target a network of regulators of T Helper 2 cell-associated cytokine production. Immunity 44, 821-832. doi: 10.1016/j.immuni.2016.01.003

Qian, L., Van Laake, L. W., Huang, Y., Liu, S., Wendland, M. F., and Srivastava, D. (2011). miR-24 inhibits apoptosis and represses Bim in mouse cardiomyocytes. J. Exp. Med. 208, 549-560. doi: 10.1084/jem.20101547

Rehli, M., Niller, H. H., Ammon, C., Langmann, S., Schwarzfischer, L., Andreesen, R., et al. (2003). Transcriptional regulation of CHI3L1, a marker gene for late stages of macrophage differentiation. J. Biol. Chem. 278, 44058-44067. doi: 10.1074/jbc.M306792200

Renard, M., Callewaert, B., Baetens, M., Campens, L., MacDermot, K., Fryns, J. P., et al. (2013). Novel MYH11 and ACTA2 mutations reveal a role for enhanced TGFbeta signaling in FTAAD. Int. J. Cardiol. 165, 314-321. doi: 10.1016/j.ijcard.2011.08.079

Schanzer, A., Simons, J. P., Flahive, J., Durgin, J., Aiello, F. A., Doucet, D., et al. (2017). Outcomes of fenestrated and branched endovascular repair of complex abdominal and thoracoabdominal aortic aneurysms. J. Vasc. Surg. S0741-5214(17)30101-5. doi: 10.1016/j.jvs.2016.12.111

Shan, K., Jiang, Q., Wang, X. Q., Wang, Y. N., Yang, H., Yao, M. D., et al. (2016). Role of long non-coding RNA-RNCR3 in atherosclerosis-related vascular dysfunction. Cell Death Dis. 7, e2248. doi: 10.1038/cddis.2016.145

Shimizu, K., Mitchell, R. N., and Libby, P. (2006). Inflammation and cellular immune responses in abdominal aortic aneurysms. Arterioscler. Thromb. Vasc. Biol. 26, 987-994. doi: 10.1161/01.ATV.0000214999.12921.4f

Sun, J., Sukhova, G. K., Yang, M., Wolters, P. J., MacFarlane, L. A., Libby, P., et al. (2007). Mast cells modulate the pathogenesis of elastase-induced abdominal aortic aneurysms in mice. J. Clin. Invest. 117, 3359-3368. doi: 10.1172/JCI 31311

Tay, Y., Rinn, J., and Pandolfi, P. P. (2014). The multilayered complexity of ceRNA crosstalk and competition. Nature 505, 344-352. doi: 10.1038/nature12986

Thulasingam, S., Massilamany, C., Gangaplara, A., Dai, H., Yarbaeva, S., Subramaniam, S., et al. (2011). miR-27b*, an oxidative stress-responsive microRNA modulates nuclear factor-kB pathway in RAW 264.7 cells. Mol. Cell. Biochem. 352, 181-188. doi: 10.1007/s11010-011-0752-2

Tung Chan, C. Y., Yee Cheuk, B. L., and Keung Cheng, S. W. (2017). Abdominal aortic aneurysm-associated microRNA-516a-5p regulates expressions of methylenetetrahydrofolate reductase, matrix metalloproteinase- 2 and tissue inhibitor of matrix metalloproteinase-1 in human abdominal aortic vascular smooth muscle cells. Ann. Vasc. Surg. S0890-5096(17)30377-1. doi: 10.1016/j.avsg.2016.10.062

van Rooij, E., Sutherland, L. B., Liu, N., Williams, A. H., McAnally, J., Gerard, R. D., et al. (2006). A signature pattern of stress-responsive microRNAs that can evoke cardiac hypertrophy and heart failure. Proc. Natl. Acad. Sci. U.S.A. 103, 18255-18260. doi: 10.1073/pnas.0608791103

Vausort, M., Wagner, D. R., and Devaux, Y. (2014). Long noncoding RNAs in patients with acute myocardial infarction. Circ. Res. 115, 668-677. doi: 10.1161/CIRCRESAHA.115.303836

Verstraeten, A., Luyckx, I., and Loeys, B. (2017). Aetiology and management of hereditary aortopathy. Nat. Rev. Cardiol. 14, 197-208. doi: 10.1038/nrcardio.2016.211

Vidigal, J. A., and Ventura, A. (2015). The biological functions of miRNAs, lessons from in vivo studies. Trends Cell Biol. 25, 137-147. doi: $10.1016 /$ j.tcb.2014.11.004

Wang, D., Deuse, T., Stubbendorff, M., Chernogubova, E., Erben, R. G., Eken, S. M., et al. (2015a). Local MicroRNA Modulation Using a Novel AntimiR-21-Eluting Stent effectively prevents experimental in-stent restenosis. Arterioscler. Thromb. Vasc. Biol. 35, 1945-1953. doi: 10.1161/ATVBAHA.115. 305597
Wang, Q., Shu, C., Su, J., and Li, X. (2015b). A crosstalk triggered by hypoxia and maintained by MCP-1/miR-98/IL-6/p38 regulatory loop between human aortic smooth muscle cells and macrophages leads to aortic smooth muscle cells apoptosis via Stat1 activation. Int. J. Clin. Exp. Pathol. 8, 2670-2679.

Wang, S., Zhang, X., Yuan, Y., Tan, M., Zhang, L., Xue, X., et al. (2015c). BRG1 expression is increased in thoracic aortic aneurysms and regulates proliferation and apoptosis of vascular smooth muscle cells through the long non-coding RNA HIF1A-AS1 in vitro. Eur. J. Cardiothorac. Surg. 47, 439-446. doi: $10.1093 /$ ejcts/ezu215

Wang, Y., Ait-Oufella, H., Herbin, O., Bonnin, P., Ramkhelawon, B., Taleb, S., et al. (2010). TGF-beta activity protects against inflammatory aortic aneurysm progression and complications in angiotensin II-infused mice. J. Clin. Invest. 120, 422-432. doi: 10.1172/JCI38136

Wang, Y., Krishna, S., Walker, P. J., Norman, P., and Golledge, J. (2013). Transforming growth factor-beta and abdominal aortic aneurysms. Cardiovasc. Pathol. 22, 126-132. doi: 10.1016/j.carpath.2012.07.005

Wang, Y. N., Shan, K., Yao, M. D., Yao, J., Wang, J. J., Li, X., et al. (2016). Long Noncoding RNA-GAS5, a novel regulator of hypertension-induced vascular remodeling. Hypertension 68, 736-748. doi: 10.1161/HYPERTENSIONAHA.116.07259

Williams, C. R., and Brooke, B. S. (2017). Effectiveness of open versus endovascular abdominal aortic aneurysm repair in population settings, A systematic review of statewide databases. Surgery S0039-6060(17)30075-2. doi: 10.1016/j.surg.2017.01.014

Wu, G., Cai, J., Han, Y., Chen, J., Huang, Z. P., Chen, C., et al. (2014). LincRNAp21 regulates neointima formation, vascular smooth muscle cell proliferation, apoptosis, and atherosclerosis by enhancing p53 activity. Circulation 130, 1452-1465. doi: 10.1161/CIRCULATIONAHA.114.011675

Wu, J., Song, H. F., Li, S. H., Guo, J., Tsang, K., Tumiati, L., et al. (2016). Progressive aortic dilation is regulated by miR-17-Associated miRNAs. J. Am. Coll. Cardiol. 67, 2965-2977. doi: 10.1016/j.jacc.2016.04.027

Yan, B., Yao, J., Liu, J. Y., Li, X. M., Wang, X. Q., Li, Y. J., et al. (2015). IncRNA-MIAT regulates microvascular dysfunction by functioning as a competing endogenous RNA. Circ. Res. 116, 1143-1156. doi: 10.1161/CIRCRESAHA.116.305510

Yu, B., Liu, L., Sun, H., and Chen, Y. (2015). Long noncoding RNA AK056155 involved in the development of Loeys-Dietz syndrome through AKT/PI3K signaling pathway. Int. J. Clin. Exp. Pathol. 8, 10768-10775.

Zampetaki, A., Attia, R., Mayr, U., Gomes, R. S., Phinikaridou, A., Yin, X., et al. (2014). Role of miR-195 in aortic aneurysmal disease. Circ. Res. 115, 857-866. doi: 10.1161/CIRCRESAHA.115.304361

Zhang, Y., Liu, Z., Zhou, M., and Liu, C. (2016). MicroRNA-129-5p inhibits vascular smooth muscle cell proliferation by targeting Wnt5a. Exp. Ther. Med. 12, 2651-2656. doi: 10.3892/etm.2016.3672

Zhao, J., Zhang, W., Lin, M., Wu, W., Jiang, P., Tou, E., et al. (2016). MYOSLID is a novel serum response factor-dependent long noncoding RNA that amplifies the vascular smooth muscle differentiation program. Arterioscler. Thromb. Vasc. Biol. 36, 2088-2099. doi: 10.1161/ATVBAHA.116.307879

Conflict of Interest Statement: The authors declare that the research was conducted in the absence of any commercial or financial relationships that could be construed as a potential conflict of interest.

Copyright (c) $2017 \mathrm{Li}$ and Maegdefessel. This is an open-access article distributed under the terms of the Creative Commons Attribution License (CC BY). The use, distribution or reproduction in other forums is permitted, provided the original author(s) or licensor are credited and that the original publication in this journal is cited, in accordance with accepted academic practice. No use, distribution or reproduction is permitted which does not comply with these terms. 